\title{
Ursodeoxycholic Acid in Patients With Treatment-Resistant Schizophrenia Suffering From Coronavirus Disease 2019: A Hypothesis Letter
}

\author{
Mohsen Khosravi* \\ Department of Psychiatry and Clinical Psychology, Zahedan University of Medical Sciences, Zahedan, Iran
}

Keywords: coronavirus disease 2019, patient, schizophrenia, treatment, ursodeoxycholic acid

OPEN ACCESS

Edited by:

Stefania Schiavone, University of Foggia, Italy

Reviewed by:

Angelo De Giorgi,

Azienda Sanitaria Locale della

Provincia di Foggia, Italy

Attilio Negri,

Azienda Socio Sanitaria Territoriale di

Mantova, Italy

*Correspondence:

Mohsen Khosrav

dr_khosravi2016@yahoo.com orcid.org/0000-0003-2970-6309

Specialty section:

This article was submitted to Molecular Psychiatry,

a section of the journal

Frontiers in Psychiatry

Received: 28 January 2021 Accepted: 01 March 2021 Published: 14 April 2021

Citation:

Khosravi M (2021) Ursodeoxycholic Acid in Patients With Treatment-Resistant Schizophrenia Suffering From Coronavirus Disease

2019: A Hypothesis Letter.

Front. Psychiatry 12:657316.

doi: 10.3389/fpsyt.2021.657316
Schizophrenia is a disabling condition with three main domains of positive, negative, and cognitive symptoms, which involves about $0.3-0.7 \%$ of the general population (1). Treatment-resistant schizophrenia (TRS) is a significant challenge in one-third of patients with schizophrenia, placing a heavy burden on families, society, and health-care professionals (2). Moreover, if these patients are infected with severe acute respiratory syndrome coronavirus 2 (SARS-CoV-2), medical treatment and psychosocial support systems will experience an increasing burden of treatment (3). Recent studies have shown that patients with schizophrenia may be vulnerable to SARS-CoV-2 infection for various reasons, including (i) poor insight and lack of decision-making capacity and effective coping skills, which lead to violation of the protective measures for inhibiting infection (e.g., physical distancing, using facial masks, and washing hands); (ii) high prevalence of comorbid metabolic disorders (more than $70 \%$ ) such as hypertension, diabetes type II, coronary heart disease, and chronic pulmonary disease; (iii) high prevalence of smoking (50-90\%); and (iv) homelessness or institutionalization (4). Although clozapine possesses more clinical superiorities than other antipsychotic medications in cases of TRS, its use during the viral pandemic is especially challenging due to the overlap between clozapine-induced side effects and the coronavirus disease 2019 (COVID-19) symptoms and sequelae, as well as practical difficulties in regular laboratory monitoring $(5,6)$. Accordingly, in the context of the COVID-19 crisis, new and effective therapeutic strategies need to be developed to treat and rescue these patients. Based on the current evidence, ursodeoxycholic acid (UDCA) seems to be an effective strategy in decreasing inflammation and avoiding cell death for patients with TRS infected with SARS-CoV-2. UDCA $\left(\mathrm{C}_{24} \mathrm{H}_{40} \mathrm{O}_{4}\right)$ is a less toxic epimer of chenodeoxycholic acid in humans, which includes $1-5 \%$ of total bile acid components (7). Recent studies have revealed that UDCA and its main conjugate (i.e., glycoursodeoxycholic acid), as cholesterol-derived bile acids, can have neuroprotective and homeostatic properties due to their capacity to inhibit glutamate release $(8,9)$. Although the mechanism of the UDCA effect has not been wholly specified yet, a recent case report (10) showed that this medication could be an effective therapeutic strategy for patients with TRS. Based on the glutamate hypothesis of schizophrenia models, some of the probable therapeutic mechanisms would include (i) a decrease in the tone of glutaminergic projection neurons and, in turn, understimulation of inhibitory GABA interneurons in the ventral tegmental area, leading to the activation of mesocortical dopamine pathway, an increase of adequate dopamine release in the prefrontal cortex, and reduction of negative and cognitive symptoms of schizophrenia (11); and (ii) a decrease in firing of cortical glutaminergic projection neurons that causes an improvement in positive symptoms of schizophrenia through dopamine mesolimbic pathway hypoactivation $(11,12)$. Moreover, recent studies demonstrated the beneficial action of UDCA in 
respiratory diseases as an antioxidant, anti-inflammatory, immunomodulatory, and anti-apoptotic agents $(13,14)$. Some of these beneficial effects are as follows: (i) airway remodeling through the efficient modulation of Th-2-derived cytokines and inhibition of apoptosis of airway epithelial cells (15) and (ii) provoking alveolar fluid clearance in lipopolysaccharide-induced pulmonary edema via ALX/cAMP/PI3K pathway, which results in the improvement of acute respiratory distress syndrome (16). In this regard, Abdulrab et al. (17) and Subramanian et al. (18) have assumed that UDCA may have promising therapeutic effects on COVID-19-induced pneumonia and related lung edema. Bile acid derivatives have also proved to be effective in preventing virus entry by reducing the adhesion of SARS-CoV-2 spike's protein receptor binding domain to its angiotensin-converting enzyme 2 consensus in vitro (19). In addition, Yadav et al. (20) suggested that chenodeoxycholate and ursodeoxycholate can be

\section{REFERENCES}

1. Faden J, Citrome L. Resistance is not futile: treatment-refractory schizophrenia-overview, evaluation and treatment. Expert Opin Pharmacother. (2019) 20:11-24. doi: 10.1080/14656566.2018.1543409

2. Kinon BJ. The group of treatment resistant schizophrenias. Heterogeneity in treatment resistant schizophrenia (TRS). Front Psychiatry. (2019) 9:757. doi: 10.3389/fpsyt.2018.00757

3. Fonseca L, Diniz E, Mendonca G, Malinowski F, Mari J, Gadelha A. Schizophrenia and COVID-19: risks and recommendations. Braz J Psychiatry. (2020) 42:236-8. doi: 10.1590/1516-4446-2020-0010

4. Khosravi M. COVID-19 pandemic: what are the risks and challenges for schizophrenia? Clin Schizophr Relat Psychoses. (2020) 14:58-9. doi: 10.3371/CSRP.KM.110320

5. Gee S, Gaughran F, MacCabe J, Shergill S, Whiskey E, Taylor D. Management of clozapine treatment during the COVID-19 pandemic. Ther Adv Psychopharmacol. (2020) 10:2045125320928167. doi: 10.1177/2045125320928167

6. Govind R, de Freitas DF, Pritchard M, Hayes RD, MacCabe JH. Clozapine treatment and risk of COVID-19 infection: retrospective cohort study. $\mathrm{Br} \mathrm{J}$ Psychiatry. (2020) 1-7. doi: 10.1192/bjp.2020.151

7. Neskorodov YB, Mardanly SG, Chuprov-Netochin RN. The experience of analyzing biological activity of ursodeoxycholic acid as part of in silico prediction of the gene expression profile. Russian J Genet. (2020) 56:116279. doi: 10.1134/S1022795420100099

8. Ackerman HD, Gerhard GS. Bile acids in neurodegenerative disorders. Front Aging Neurosci. (2016) 8:263. doi: 10.3389/fnagi.2016.00263

9. Silva SL, Vaz AR, Diógenes MJ, van Rooijen N, Sebastião AM, Fernandes A, et al. Neuritic growth impairment and cell death by unconjugated bilirubin is mediated by NO and glutamate, modulated by microglia, and prevented by glycoursodeoxycholic acid and interleukin-10. Neuropharmacology. (2012) 62:2398-408. doi: 10.1016/j.neuropharm.2012.02.002

10. Khosravi M. Ursodeoxycholic acid augmentation in treatmentrefractory schizophrenia: a case report. J Med Case Rep. (2020) 14:137. doi: 10.1186/s13256-020-02484-9

11. Ellaithy A, Younkin J, Gonzalez-Maeso J, Logothetis DE. Positive allosteric modulators of metabotropic glutamate 2 receptors in schizophrenia treatment. Trends Neurosci. (2015) 38:506-16. doi: 10.1016/j.tins.2015.06.002

12. Lisman JE, Coyle JT, Green RW, Javitt DC, Benes FM, Heckers S, et al. Circuit-based framework for understanding neurotransmitter and risk gene interactions in schizophrenia. Trends Neurosci. (2008) 31:23442. doi: 10.1016/j.tins.2008.02.005

13. Talebian R, Panahipour L, Gruber R. Ursodeoxycholic acid attenuates the expression of proinflammatory cytokines in periodontal cells. J Periodontol. (2020) 91:1098-4. doi: 10.1002/JPER.19-0013 potential candidates to hinder the survival of SARS-CoV-2 via disrupting the structure of envelope protein of SARS-CoV-2 and facilitating the entry of solvents/polar inhibitors into the viral cell. Interestingly, Rigamonti et al. (21) recently found quite low rates of symptomatic SARS-CoV-2 infection in patients with biliary cholangitis treated with UDCA. In total, these findings may highlight the emergence of novel therapeutic strategies against COVID-19 among patients with TRS. However, further studies are needed, particularly regarding efficacy and tolerability of UDCA in this group of patients.

\section{AUTHOR CONTRIBUTIONS}

MKH conceptualized the opinion and wrote the manuscript. The author also approved the final version of the submitted manuscript.

14. Kim YJ, Jeong SH, Kim E, Kim EJ, Cho JH. Ursodeoxycholic acid suppresses epithelial-mesenchymal transition and cancer stem cell formation by reducing the levels of peroxiredoxin II and reactive oxygen species in pancreatic cancer cells. Oncol Rep. (2017) 38:3632-8. doi: 10.3892/or.201 7.6045

15. Işik S, Karaman M, Micili SÇ, Çaglayan-Sözmen S, Bagriyanik HA, ArikanAyyildiz Z, et al. Beneficial effects of ursodeoxycholic acid via inhibition of airway remodelling, apoptosis of airway epithelial cells, and Th2 immune response in murine model of chronic asthma. Allergol Immunopathol. (2017) 45:339-49. doi: 10.1016/j.aller.2016.12.003

16. Niu F, Xu X, Zhang R, Sun L, Gan N, Wang A. Ursodeoxycholic acid stimulates alveolar fluid clearance in LPS-induced pulmonary edema via ALX/cAMP/PI3K pathway. J Cell Physiol. (2019) 234:20057-65. doi: 10.1002/jcp.28602

17. Abdulrab S, Al-maweri S, Halboub E. Ursodeoxycholic acid as a candidate therapeutic to alleviate and/or prevent COVID-19-associated cytokine storm. Med Hypotheses. (2020) 143:109897. doi: 10.1016/j.mehy.2020.109897

18. Subramanian S, Iles T, Ikramuddin S, Steer CJ. Merit of an ursodeoxycholic acid clinical trial in COVID-19 patients. Vaccines. (2020) 8:320. doi: $10.3390 /$ vaccines 8020320

19. Carino A, Moraca F, Fiorillo B, Marchianò S, Sepe V, Biagioli M, et al. Hijacking SARS-Cov-2/ACE2 receptor interaction by natural and semisynthetic steroidal agents acting on functional pockets on the receptor binding domain. Front Chem. (2020) 8:572885. doi: 10.3389/fchem.2020.5 72885

20. Yadav R, Choudhury C, Kumar Y, Bhatia A. Virtual repurposing of ursodeoxycholate and chenodeoxycholate as lead candidates against SARSCov2-Envelope protein: a molecular dynamics investigation. J Biomol Struct Dyn. (2020) 38:1-12. doi: 10.1080/07391102.2020.1868339

21. Rigamonti C, Cittone MG, De Benedittis C, Rizzi E, Casciaro GF, Bellan M, et al. Rates of symptomatic SARS-CoV-2 infection in patients with autoimmune liver diseases in Northern Italy: a telemedicine study. Clin Gastroenterol Hepatol. (2020) 18:2369-71.e1. doi: 10.1016/j.cgh.2020. 05.047

Conflict of Interest: The author declares that the research was conducted in the absence of any commercial or financial relationships that could be construed as a potential conflict of interest.

Copyright (c) 2021 Khosravi. This is an open-access article distributed under the terms of the Creative Commons Attribution License (CC BY). The use, distribution or reproduction in other forums is permitted, provided the original author(s) and the copyright owner(s) are credited and that the original publication in this journal is cited, in accordance with accepted academic practice. No use, distribution or reproduction is permitted which does not comply with these terms. 